\title{
Role of Standard Radiation Safety Practices in Public Health: An Experience of a Tertiary Care Teaching Hospital
}

\author{
Libert A Gomes
}

\begin{abstract}
lonizing radiation is employed for diagnostic and therapeutic purposes round the clock in hospitals. Hence, it is the prime responsibility of the hospital management to ensure the safety of the patients, staff, visitors, public, and the environment. Patient relatives and the public/visitors who are not concerned with medical use of radiation can become vulnerable to stochastic effects of scattered radiation close to therapeutic or diagnostic radiological facilities. This article highlights radiation safety measures that have public health relevance in hospitals having both diagnostic and therapeutic radiological facilities.
\end{abstract}

Keywords: As low as reasonably achievable, Optimum dose limits, Radiation, Radiation safety officer, Radioactive waste, Shielding.

How to cite this article: Gomes LA. Role of Standard Radiation Safety Practices in Public Health: An Experience of a Tertiary Care Teaching Hospital. Int J Res Foundation Hosp Healthc Adm 2017;5(2):73-76.

Source of support: Nil

Conflict of interest: None

\section{INTRODUCTION}

Radiation and radioisotopes have been extensively used in the field of medicine, industries, agriculture, and research. The probability of human beings getting exposed to radiation is also on the rise. ${ }^{1}$ The large public health problem created by the Chernobyl accident alongside radiation-induced deaths and diseases impacted the mental health of 350,000 people who moved out of the contaminated areas when relocation proved to be deeply traumatic experience. ${ }^{2}$

Radiation risks are reviewed by international and national organizations, such as the International Commission on Radiological Protection, the United Nations Scientific Committee on the Effects of Atomic Radiation, the UK's Radiation Protection Division of the Health Protection Agency (formerly the National

Associate Professor

Department of Hospital Administration, JSS Medical College Mysuru, Karnataka, India

Corresponding Author: Libert A Gomes, Associate Professor Department of Hospital Administration, JSS Medical College Mysuru, Karnataka, India, Phone: +918212548338, e-mail: libertanilgomes@jssuni.edu.in
Radiological Protection Board) and the National Council on Radiation Protection and Measurement in the USA. It is an important function of these bodies to continually assess and review publications from all over the world on the effects of exposure to ionizing radiation on human health and to reach a balanced view of the risks involved. ${ }^{3}$ The Indian regulatory board is the Atomic Energy Regulatory Board (AERB). The mission of the Board is to ensure that the use of ionizing radiation and nuclear energy in India does not cause undue risk to health and environment. The regulatory bodies have laid down duties for the radiation safety officer (RSO) and safe dose limits for radiation workers and the general public $(1 \mathrm{mSv} / \mathrm{yr}){ }^{4}$

The annual effective dose for the public should not exceed $1 \mathrm{mSv}$ for whole body, $50 \mathrm{mSv}$ for skin, and $15 \mathrm{mSv}$ for lens of the eye. ${ }^{5}$ However, natural radiation (atmospheric) background dose should not be considered in the dose limits for occupational workers and the members of the public (in India it is about $2.4 \mathrm{mSv} / \mathrm{yr}$ on average). ${ }^{1}$

The Department of Atomic Energy and Emergency Response Centers (DAE-ERCs) has spread all over India for effective response to any nuclear or radiological emergency, anywhere in the country. ${ }^{1}$ To address challenges in the medical system and the public's concerns, the ABMS (American Board of Medical Specialties) has undertaken MOC (Maintenance of Certification) program for diagnostic radiology, radiation oncology, and radiologic physics. ${ }^{6}$ The "US Public Health Emergency Medical Countermeasures Enterprise" has prioritized the development of expanded spectrum radionuclide decorporation agents as a countermeasure against nuclear threats, which greatly enhances the elimination of internalized radio nuclides through urine and feces. ${ }^{7}$

\section{MATERIALS AND METHODS}

A prospective study was carried out for a period of 6 months (i.e., May 7-October 7). The methodology adopted is direct informal interviews with the consultants, RSO, and technicians working in the department. Records and registers maintained in the department were perused to obtain relevant information. 


\section{OBSERVATIONS AND DISCUSSION}

Observations were made with relevance to public health in the following departments:

- Nuclear Medicine Unit: Planning considerations of nuclear medicine facility in the hospital have been done to ensure safety of workers and the public. It conforms to the specifications and guidelines given by the regulatory authority AERB. ${ }^{8}$ The facility is situated far away from certain areas of the hospital like outpatient departments (especially Pediatrics, Obstetrics and Gynecology), maternity wards, and labor room. The walls, floors, and doors have hard, washable, nonporous and leak-proof covering. Plumbing lines and drain pipes are made up of leak-proof, corrosionresistant material. The drain pipes from toilets located in patient areas (subjected to radioisotope like Iodine $131-\mathrm{I}^{131}$ ) open into a delay tank (interim storage tank) and thereafter disposed into the general sewage line when the level of radioactivity is harmless.

Policies and procedures adopted in the hospital focus toward ensuring that the workers and public are not exposed to radiation in excess of limits specified by the competent authority AERB. Salient features of the hospital policy are as follows:

- The RSO organizes radiation protection programs. The duties of the RSO include maintenance of records of doses of workers; inventory of radioactive sources received, used, and disposed; unusual incident report; cause of such an incident and remedial measures taken. The RSO also coordinates with authorized personnel by competent authority for inspection of the facility. The RSO also ensures that records of area monitoring (i.e., treatment room, nursing station, public areas, storage area, etc.), contamination monitoring, logbooks, and inventory records are kept available at the time of inspection.

- Waste disposal policies and procedures adopted in the hospital comply with Atomic Energy (safe disposal of radioactive wastes) Rules 1987. The RSO assists/advices the Consentee (Head of the Institution) in obtaining the authorization from the competent authority for disposal of radioactive waste.

Mode of waste disposal: Solid wastes like syringes, vials, swabs containing short-lived radioisotopes, such as $\mathrm{I}^{131}$ technetium 99 (Tc-99m), molybdenum (Mo-99), etc., are stored in a lead container for a period of 10 half lives. This is as per the guidelines. After that they are disposed of as per biomedical waste management guidelines. In case of liquid waste generated by patients undergoing treatment for malignant disorders of thyroid, patients are isolated and are allowed to use separate toilets. The sewage from the toilets is collected in a separate tank called "delay tank" which is for interim storage. When the level of radioactivity comes down and reaches the desired limits (monthly concentration at 22.2 $\mathrm{MBqm}^{-3}$; $\mathrm{MBq}=\mathrm{Mega}$ Becquerel) it is discharged into sewage lines by dilution and overflow technique. Low-activity shortlived isotopes where activity is less than microcuries are disposed of into sanitary sewage line with adequate flushing with water. This conforms to the BARC guidelines for disposal of waste in nuclear medicine (Fig. 1). ${ }^{9}$

- Radiotherapy units like teletherapy/brachytherapy: The hospital has two teletherapy units, one of which uses a radioactive source Cobalt-60 (Co60) and the other generates high-energy $\mathrm{X}$-rays (linear accelerator) as an external source of radiation. The manufacturer obtains type approval certificate from the competent authority before selling the equipment to the hospital. Installation of units is done only after obtaining approval from the AERB. The doors are equipped with warning light and radiation symbol to caution patient attendees/visitors that the irradiation procedure is in progress and prohibits entry. In addition, it has got a $2 \mathrm{~mm}$ lead sheet covering which gives adequate protection against scattered radiation which can produce possible harmful effects to persons / visitors outside the door if at all lead sheet covering is not provided. The treatment room has got safety interlocks at doors to prevent inadvertent entry of visitors/patient attendees during irradiation. The hospital policies and procedures in the functioning of teletherapy/brachytherapy/X-ray units comply with

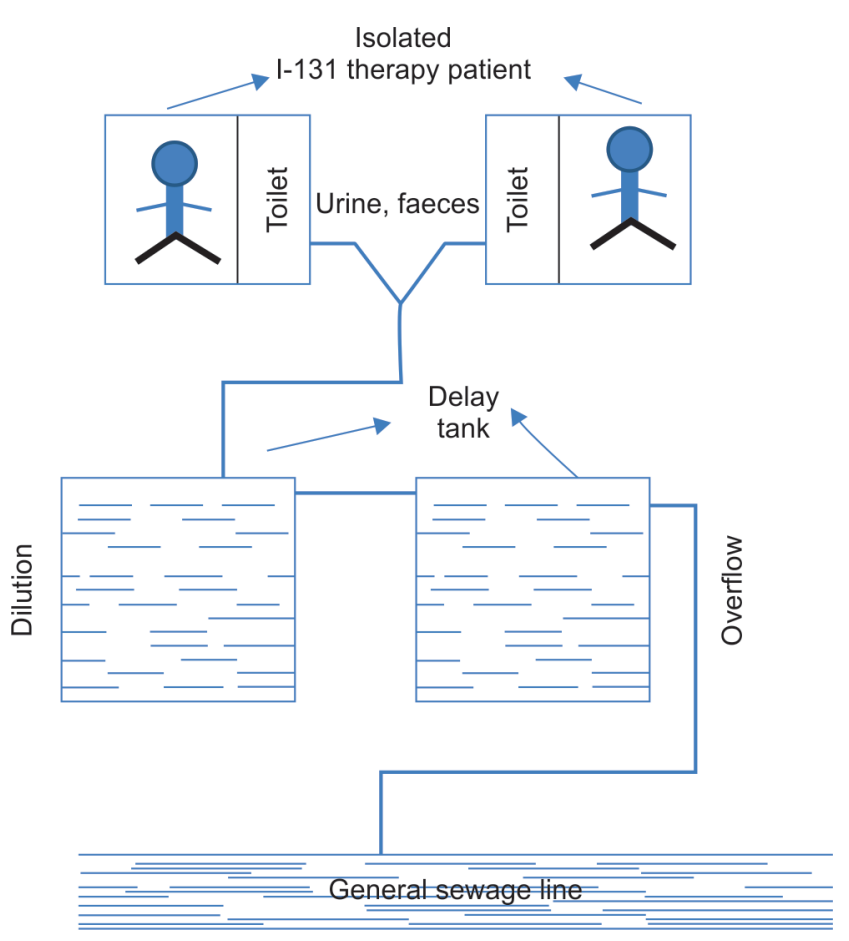

Fig. 1: Delay tank for liquid radioactive waste disposal 


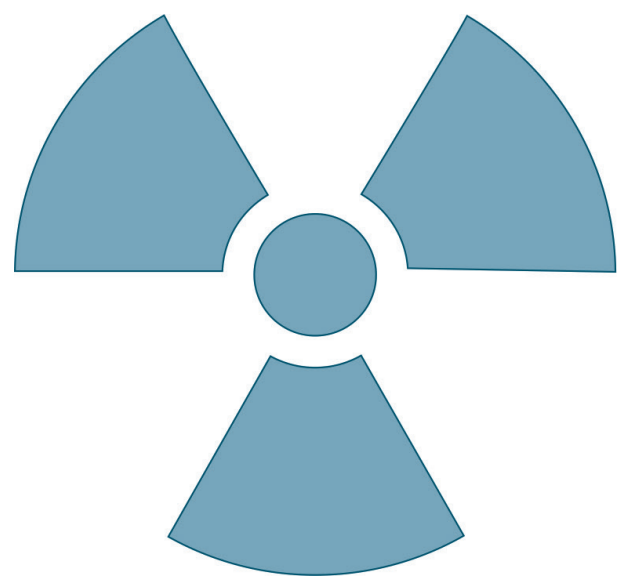

Fig. 2: Radiation symbol

the guidelines mentioned in AERB Safety Code No SC/MED1, 2, 3 (Fig. 2). ${ }^{10-12}$

Shielding is of paramount importance in teletherapy/ brachytherapy therapy units as the intensity of radiation employed is very high (megaelectronvolt) and the routine brick wall thickness of $23 \mathrm{~cm}$ provides no protection against scattered radiation. This can be detrimental to people passing by outside the room (workers/visitors). Shielding requirements are calculated after taking several factors into consideration so as to minimize the radiation outside the room (ALARA—As Low As Reasonably Achievable). They are workload, occupancy, nature of source, energy of radiation emitted, proximity to corridors where there is constant movement of visitors/public. Entrance to the treatment room is indirect, i.e., a maze is present in case of brachytherapy/teletherapy units to minimize shielding requirements for the main entrance door (Fig. 3).

Waste disposal in radiotherapy units: In the brachytherapy unit, prior to disposal, the institution has to submit the authorization form for waste disposal with an undertaking. The institution should also obtain transport authorization form from the AERB. ${ }^{13}$ (Note: The decayed source from brachytherapy units is Iridium 192 with an activity of 1-2 curie.) The documents to be sent along with the consignment are (i) AERB authorization. (ii) Form $\mathrm{S} 1$ in triplicate. (Note: This is a requisition for waste collection to BARC facilities, Central Waste Management facilities, Kalpakkam.) The wastes are categorized and identified by color tags/code on the original transport container depending on the amount of radiation recorded at $1 \mathrm{~mm}$ from the external surface of the container. (iii) Transport Emergency card (TREM card), i.e., action to be taken in case of emergency situations like damage, fire engulfment, theft, unclaimed package in areas of public domain in situations where one has to rescue the injured and provide medical aid, fire containment exercise; and cordon off at a minimum $5 \mathrm{~mm}$ radius from an unclaimed

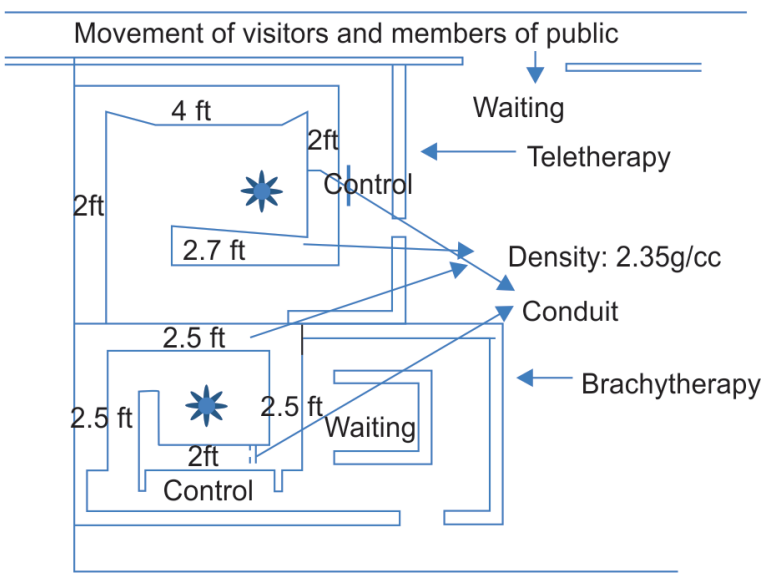

Fig. 3: Layout of the brachytherapy/teletherapy units with shielding

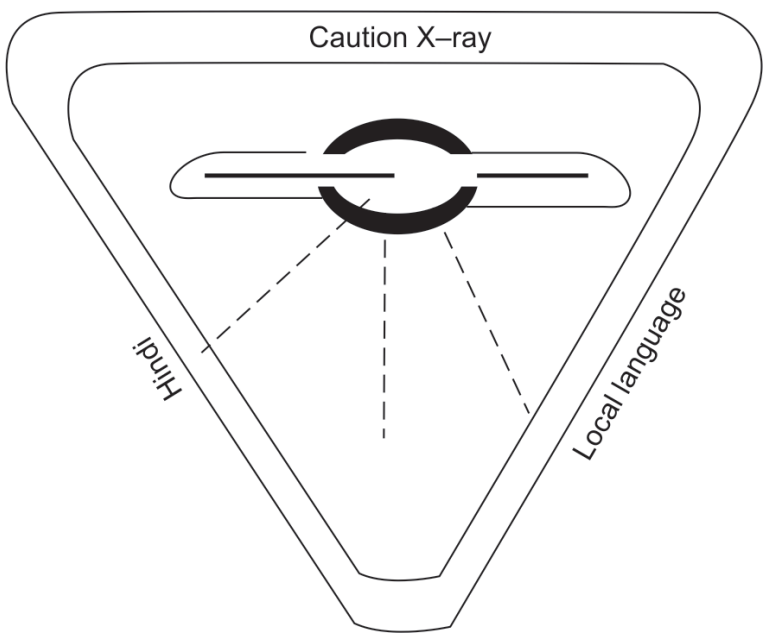

Fig. 4: "Caution Symbol" for X-ray unit

package. The receiver of the package should also be informed. The radioactive source is packed in original transport containers and transported by road and finally delivered to Central Waste Management Facilities, Kalpakkam, through the suppliers. The transport of radioactive sources is in accordance with specifications of AERB safety code for transport of radioactive material. ${ }^{14}$ In case of teletherapy, the decayed source is Cobalt 60 . The source is packed in original transport containers and sent to Canada for ultimate disposal.

- Other radiology units like X-ray/computed tomography scan: The doors have a lead lining $2 \mathrm{~mm}$ thick. The door displays X-ray symbol with a message "Caution X-ray" (Fig. 4). The message is written in two different languages (Hindi and English) for better understanding of visitors. One of the policies adopted in X-ray unit is that the relatives/visitors of the patient are instructed to hold crying/restless children. Personal protective devices are provided to these people rendering help within the room during $X$-ray procedure. This conforms to AERB safety code for medical diagnostic $X$-ray equipment and installations. ${ }^{12}$ 


\section{CONCLUSION}

A well-established radiation safety program is essential to fulfill the radiation protection requirements and to derive optimum diagnostic and therapeutic benefits from the use of radiation. Violation of the guidelines and endangering the health and safety of health care workers, patients, visitors, and public is unjustifiable and punishable under section 24, 25, 26 of Atomic Energy Act, 1962.

\section{REFERENCES}

1. Bhatt BC. Role of BARC in quality assurance and safety in medical applications of Ionizing radiation. In 50 years of Cancer Control in India. India: Ministry of Health and Family Welfare; 2002. [cited 2008 Jun]. Available from: http://mohfw. nic.in/pg105to121.pdf.

2. World Health Organization. Joint news release WHO/IAEA/ UNDP. Chernobyl-The true scale of the accident. Geneva: WHO; 2005. [cited 2008 Jan]. Available from: http://www. who.int/mediacentre/news/releases /2005/pr38/en/index. html.

3. Wall BF, Kendall GM, Edwards AA, Bouffler S, Muirhead CR, Meara JR. What are the risks from medical X-rays and other low dose radiation? Br J Radiol 2006 Apr;79(940):285-294.

4. Grover SB, Kumar J, Gupta A, Khanna L. Protection against radiation hazards: regulatory bodies, safety norms, does limits and protection devices. Indian J Radiol Imaging 2002 May;12(2):157-167.

5. World Health Organization. Geneva: safety in healthcare laboratories. 1st ed. New Delhi: AITBS Publishers; 2003. p. 75.
6. Srife JL, Kun LE, Becker J,Dunnick NR, Bosma J, Hattery RR. The American Board of radiology perspective on maintenance of certification: part IV—practice quality improvement in diagnostic radiology. Am J Roentgol 2007 May;188(5): 1183-1186.

7. Cassatt DR, Kaminski JM, Hatchett RJ, DiCarlo AL, Benjamin JM, Maidment BW. Medical countermeasures against nuclear threats: radionuclide decorporation agents. Radiat Res 2008 Oct;170(4):540-548.

8. Atomic Energy Regulatory Board Safety Code. Nuclear medicine facilities. Code No AERB/SC/MED-4 (Rev. 1). Mumbai: AERB; 2001. pp. 11-27.

9. Nagalakshmi B. Nuclear Medicine waste disposal. In: Training Workshop on Radiation Safety in Nuclear Medicine and Radiation Safety officer certification. Mumbai: BARC; 2003. pp. 16.1-16.4.

10. Atomic Energy Regulatory Board. Safety code for teletherapy. Code No AERB/SC/MED-1 (Rev. 1). Mumbai: AERB; 2001. pp. 6-14.

11. Atomic Energy Regulatory Board. Safety code for brachytherapy. Code No AERB/SC/MED-2 (Rev. 1). Mumbai: AERB; 2001. pp. 6-25.

12. Atomic Energy Regulatory Board. Safety code for medical diagnostic $X$ ray installations. Code No AERB/SC/MED-1 (Rev. 1). Mumbai: AERB; 2001. pp. 6-26.

13. Atomic Energy Regulatory Board. Safety code for safe disposal of radioactive wastes. Mumbai: AERB; 1987. [cited 2008 Jun]. Available from: http://www.dae.gov.in/rules/waste.pdf.

14. Atomic Energy Regulatory Board. Safety code for safe transport of radioactive material. Code No AERB/NRF-TS/SC-1 (Rev. 1). Mumbai: AERB; 2008. [cited 2008 Jun]. Available from: http://www.aerb.gov.in/cgi.bin/Transport/TRANSPORT. 